\title{
AS PRINCIPAIS TENDÊNCIAS PEDAGÓGICAS DA EDUCAÇÃo FÍSICA E SUA RELAÇÃO COM A INCLUSÃO
}

\author{
Ana Cláudia Raposo de Melo, Universidade de Brasília - UnB, Brasília, Distrito Federal - Brasil \\ Albertina Mitjans Martinez, Universidade de Brasília - UnB, Brasília, Distrito Federal - Brasil
}

\section{RESUMO}

As aulas de Educação Física apresentaram por muito tempo as características tecnicistas e esportivistas, mas a partir da década de 80 surgirão novas abordagens pedagógicas que não apenas questionaram os conteúdos esportivos e os métodos de ginástica, mas apresentaram novas propostas. Apesar do surgimento das novas abordagens da educação física, a inclusão dos alunos com necessidades especiais, bem como de todos os alunos indistintamente ainda mereçe discussão. $\mathrm{O}$ objetivo deste artigo é apresentar a relação direta ou indireta existente entre as principais abordagens da Educação Física e as possibilidades de inclusão dos alunos com necessidades educativas especiais, visando destacar aqueles que podem favorecer efetivamente a participação indistinta dos todos os alunos nas aulas de Educação Física Escolar. Para isto foram realizadas constatações e inferências na literatura sobre a preocupação com a necessidade de "inclusão" nas abordagens pedagógicas da educação física, evidenciando-se que a maioria delas, não apresenta evidencias claras sobre como a inclusão deveria acontecer, existindo em algumas das abordagens apenas a ideia de "não exclusão".

Palavras-Chave: Educação Física, Inclusão, Abordagens pedagógicas.

\section{THE MAIN TRENDS OF PHYSICAL EDUCATION EDUCATIONAL AND ITS RELATIONSHIP WITH THE INCLUSION}

\begin{abstract}
The Physical Education classes had long sport and technologic characteristics, but from the 80 new pedagogical approaches will emerge that questioned not only the content and methods of sports gymnastics, but presented new proposals. Despite the emergence of new approaches to Physical Education, the inclusion of students with special needs, as well as all students without distinction deserves further discussion. The objective of this paper is to present a direct or indirect relation between the main approaches of physical education and the possibilities of inclusion of pupils with special educational needs, aiming to highlight those that can effectively encourage the participation of all students indistinct in Physical Education classes school. To this were made findings and inferences in the literature about the concern with the need for "inclusion" in physical education teaching approaches, showing that most of them presents no clear evidence on how inclusion should happen, existing in some of the approaches just the idea of "non-exclusion".
\end{abstract}

Key -Words: Physical Education, Inclusion, Pedagogical approaches. 


\section{INTRODUÇÃO}

A história da educação física nas escolas brasileiras avançou com a reforma Couto Ferraz em 1851, ${ }^{1}$ tendo nesta época como conteúdo específico os métodos de ginástica. Porém sua consolidação aconteceu após a reforma de 1882, onde esta disciplina passou a ser obrigatória para ambos os sexos

e em todas as etapas do ensino. ${ }^{1}$ As aulas de educação física, mantiveram por muito tempo as características tecnicistas e esportivistas, mas a partir da década de 80 as discussões sobre a educação física ganharam uma característica mais crítica e política, onde os conteúdos esportivos e os métodos de ginástica foram questionados.

A educação física escolar, apesar do surgimento das novas abordagens que propuseram inovação na forma de atuação, manteve a historia de exclusão dos alunos menos hábeis, dos alunos com necessidades educativas especiais, enfim, esta atividade não contemplava a todos os alunos de forma indistinta. Apesar dos avanços da educação física escolar, estes não foram suficientes, pois ainda temos lacunas consideráveis na inclusão nestas aulas, assim como no ambiente escolar. ${ }^{2}$

Faria $\mathrm{Jr}^{3}{ }^{3}$ observa que parece existir uma tendência em associar a inclusão apenas aos alunos com necessidades especiais, tanto no senso comum como educacional, em especial na educação física, esquecendo a exclusão de alunos menos hábeis, obesos, meninas, entre outros.

Segundo Mantoan ${ }^{4}$ para que as lacunas do processo de inclusão sejam minimizadas, o primeiro passo é entender que a inclusão deve ser total, independentemente do conteúdo escolhido, os processos de ensino-aprendizagem devem considerar as características dos alunos em todas as dimensões (cognitiva, corporal, afetiva, social e estética), garantindo assim a participação de todos.

Independentemente das diferentes abordagens que existem na educação física, a concepção de inclusão total tem gerado interessantes e profundos debates, sendo necessário reconhecer a ênfase da autora, no fato de que o professor deverá fazer as adequações necessárias nas regras, nas atividades, na utilização do espaço, utilizando materiais para estimular tanto o aluno com necessidades especiais, como todo o grupo, favorecendo assim a formação integral do aluno.

O termo "aluno com necessidades especiais" define, nos dizeres de Soler, ${ }^{5}$ os alunos que apresentem dificuldades maiores que os demais alunos no domínio das aprendizagens curriculares 
correspondentes à sua idade e necessita, para minimizar estas dificuldades, de algumas adaptações que facilite sua aprendizagem.

Mediante estas colocações, o termo "aluno com necessidades especiais" se mostrou mais adequado no contexto deste trabalho, concordando com Soler, ${ }^{5}$ ao destacar que devemos focar os recursos que a pessoa necessita para minimizar suas dificuldades ou limitações em todos os aspectos da sua vida, inclusive a área educacional.

O objetivo deste artigo é apresentar a relação direta ou indireta existente entre as principais abordagens da educação física e as possibilidades que brinda para a inclusão dos alunos com necessidades especiais, visando destacar aqueles que podem favorecer efetivamente a participação indistinta dos todos os alunos nas aulas de Educação Física escolar.

\section{AS PRINCIPAIS ABORDAGENS DA EDUCAÇÃO FÍSICA E SUA RELAÇÃO COM A INCLUSÃO}

Segundo Darido ${ }^{6}$ as abordagens pedagógicas da Educação Física Escolar podem ser definidas como movimentos engajados para renovação teórico-prática com o objetivo de estruturação do campo de seus conhecimentos que são específicos da educação física, caracterizam a representação de momentos históricos e políticos, modelos pedagógicos, enfim a forma e estrutura da educação física em ambiente escolar em diferentes momentos e contextos históricos.

Tendo em conta as fases e abordagens que serão analisados neste trabalho consideramos necessário inicialmente esclarecer que as fases higienista, militarista, esportivização, escola nova e psicomotricidade, seguiram um movimento político ou educacional, não apresentando um único representante ou atutor já que estas foram conceitualizações resultantes de momentos vividos pela educação física, que são apontados por diferentes autores na literatura.

As abordagens que surgiram posteriormente ao movimento da psciomotricidade, incluindo a construtivista, desenvolvimentista, crítico-superadora, crítico-emancipatória, ensino aberto, motricidade humana, sistêmica, jogos cooperativos, saúde renovada e educação física plural, geralmente apresentam como formuladores um autor principal, mesmo que na literatura possamos encontrar referências direcionadas a diferentes autores. Alguns dos elementos destas abordagens são 
destacados nos parâmetros curriculares nacionais, que foram idealizados para nortear a atuação do profissional de educação física.

No século XIX a educação física tornou-se obrigatória, mas apesar desta obrigatoriedade, os alunos que após uma perícia fossem declarados incapazes eram automaticamente dispensados. ${ }^{7}$ Esta atitude caracterizava claramente a exclusão das aulas de educação física caso os alunos que apresentasse alguma doença ou limitação física. Assim podemos verificar que a exclusão de alunos nas aulas de educação física possui um longo passado, o qual se manteve no século XX.

$\operatorname{Costa}^{8}$ aponta que as aulas de educação física nesta época reproduziam a cultura sexista dominante, contribuindo para neutralização das meninas, pois as atividades propostas para aula de educação física valorizavam ou priorizarem a força, a velocidade, agilidade. Somados a esse fato, houve também a realização das aulas separadas, bem como a divisão da quadra, onde esta metade do tempo das aulas a quadra era utilizada pelos meninos e o outro período pelas meninas. ${ }^{9}$

No início do Século XX inicia-se na educação física brasileira a concepção higienista, onde os objetivos principais eram preparar homens fortes, ágeis e saudáveis, o que limitava a participação de pessoas com alguma doença ou deficiência nas aulas de educação física. ${ }^{10} \mathrm{Na}$ concepção militarista, que objetivava o desenvolvimento da aptidão física, preparo de uma juventude forte, saudável e pronta para defender a pátria, também não permitia que alunos com baixa aptidão física, deficiências ou doenças participassem das aulas de educação física escolar. ${ }^{6,11}$

A fase da esportivização que surgiu na educação física década de 70, apresentava como objetivo principal o desempenho atlético-esportivo, a seleção dos mais habilidosos, o alto rendimento, a repetição e a perfeição dos movimentos. Desta forma, a proposta desta fase não possibilitava a inclusão de todos os alunos nas aulas de educação física, pois privilegiava os alunos com potencial atlético. ${ }^{6}$

Nas etapas da educação física citadas anteriormente havia a preocupação principal com a saúde, com a melhora das valências físicas e aprimoramento motor. A tentativa de mudança deste cenário surgiu em meados do Século XX, onde a escola nova propos, teoricamente, uma troca do padrão biológico para sociocultural, objetivando o desenvolvimento da criança. Esta proposta possibilitaria a participação dos alunos com necessidades educativas especiais, porém o discurso não condizia com a prática que manteve o padrão das fases anteriores. ${ }^{6,10}$

Conexões: revista da Faculdade de Educação Física da UNICAMP, Campinas, v. 10, n. 2, p. 180-195 maio/ago. 2012.183 ISSN: 1983-9030 
Em oposição à vertente mais tecnicista, esportivista e biologista surgem novos movimentos na Educação Física Escolar no final da década de 70, inspirados no momento histórico social por qual passou o país. ${ }^{6,10}$

A exemplo disto tem a psicomotricidade, que surgiu na década de 70 e objetivava o desenvolvimento da criança, utilizando os movimentos espontâneos. No Brasil esta abordagem substitui o conteúdo predominantemente esportivo para a valorização da aquisição de esquema motor, lateralidade, consciência corporal e coordenação viso-motora. Esta abordagem valorizou o processo de aprendizagem e não apenas a execução isolada de um gesto técnico. ${ }^{12}$ As propostas da psicomotricidade, onde o aprendizado, a consciência corporal é valorizada, favoreceria a participação de todos os alunos nas aulas de educação física, independente de suas limitações. ${ }^{10,13,14}$ Esta inclusão não acontece de forma ampla, mas segundo, ${ }^{15}$ a psicomotricidade pode ser considerada a "primeira infância" da educação física escolar inclusiva.

A partir da valorização do humano e do processo de ensino aprendizagem na psicomotricidade, nas últimas duas décadas do século XX, um número considerável de abordagens pedagógicas na área da educação física foram propostas com intuito de contrapor-se aos modelos biológicos, tecnicista e voltados para o esporte, os quais não permitiam a participação de todos os alunos nas aulas de educação física escolar.

Ainda sob a influência da psicomotricidade foi proposta em 1989, por João Batista Freire, ${ }^{16}$ a abordagem denominada construtivista, proposta em oposição às linhas anteriores da Educação Física escolar. Esta aponta a importância da Educação Física na escola considerar o conhecimento motor e cultural que a criança já possui. Desta forma, a Educação física deve resgatar a cultura de jogos e brincadeiras dos alunos, incluindo as brincadeiras de rua, os jogos com regras, os jogos cantados, dentre outras atividades que compõem o universo cultural dos alunos. ${ }^{16} \mathrm{~A}$ abordagem construtivista propõe que as habilidades motoras sejam desenvolvidas num contexto de jogo e brincadeira, considerando o estágio de desenvolvimento da criança, desta forma possibilita, apesar de não haver referencia direta à participação de todos os alunos, pois nesta abordagem as atividades podem ser planejadas e executadas dentro do padrão de desenvolvimento dos alunos.

Para a abordagem desenvolvimentista, segundo Go Tani, ${ }^{17}$ idealizador dos pensamentos que construíram esta abordagem, a Educação Física deve proporcionar ao aluno condições para que seu Conexões: revista da Faculdade de Educação Física da UNICAMP, Campinas, v. 10, n. 2, p. 180-195 maio/ago. 2012.184 ISSN: 1983-9030 
comportamento motor seja desenvolvido através da interação entre a diversificação e a complexidade dos movimentos. Assim, o principal objetivo da Educação Física,neste caso, é oferecer experiências de movimento adequadas ao seu nível de crescimento e desenvolvimento, a fim de que a aprendizagem das habilidades motoras seja alcançada. ${ }^{17}$ Como conteúdo propõe o desenvolvimento das habilidades básicas, habilidades especificas, jogo, esporte e dança, visando caracterizar a progressão normal do crescimento físico, desenvolvimento e ampliação do repertório motor, cognitivo e afetivo-social e em função destas características, sugerir aspectos ou elementos relevantes para a estruturação da Educação Física em ambiente escolar. ${ }^{17}$

A proposta desenvolvimentista recomenda para a Educação Física escolar o desenvolvimento de um plano de aula que contemple o desenvolvimento motor através da diversidade e da complexidade de movimentos. Este deve oferecer experiências de movimentos adequados ao estágio de crescimento e de desenvolvimento dos alunos, desta forma permite que os alunos em diferentes fases de desenvolvimento motor, com habilidades motoras variadas, com necessidades educativas especiais, ou qualquer outra característica, participem efetivamente das aulas de educação física.

A abordagem crítico-superadora, que foi elaborada na Universidade Federal do Recife e na Universidade Federal de Santa Maria por um grupo de autores intitulado de Coletivo de Autores, propõe como objetivo o entendimento da Educação Física como uma disciplina que trata do conhecimento denominado de cultura corporal, o qual tem como temas, o jogo, a ginástica, o esporte e a dança. ${ }^{10}$ Esta abordagem propõe que o aluno não seja um mero reprodutor e sim participe do processo educacional, sugerindo adequações pedagógicas e discutindo os conteúdos propostos.

Quanto à organização do currículo e seleção de conteúdo, a proposta crítico-superadora ressalta a necessidade do aluno em confrontar os conhecimentos do senso comum com o conhecimento científico, ampliando assim seu conhecimento sobre a cultura de movimento, considerando a relevância social dos conteúdos e sua adequação às características sociocognitivas dos alunos. Por considerar a relevância social do conteúdo, bem como as diversas características dos alunos possibilita ao aluno sugerir as adequações pedagógicas que necessita e particpar da escolha dos conteúdos, gerando assim uma participação de todos os alunos independente da limitação que possa apresentar.

A abordagem crítico-emancipatória na visão de Elenor Kunz, principal articuladora nesta abordagem, visa atingir as finalidades da Educação Física Escolar, associada à proposta de reverter a Conexões: revista da Faculdade de Educação Física da UNICAMP, Campinas, v. 10, n. 2, p. 180-195 maio/ago. 2012.185 ISSN: 1983-9030 
imagem do esporte voltado apenas para o alto rendimento ${ }^{19}$ e tem por objetivo a formação de sujeitos críticos e autônomos para transformação (ou não) da realidade em que estão inseridos, por meio de uma educação de caráter crítico e reflexivo. ${ }^{20}$

Esta abordagem destaca que a prática de atividade física e esportiva nas aulas de educação física deve ser aberta à participação de todos os interessados, apontando claramente a possibilidade de participação de todos os alunos, independente de deficiência, dificuldade motora, baixa aptidão física, enfim não deve haver seleção ou exclusão dos alunos por qualquer critério. ${ }^{20}$

O ensino aberto, sugerido por Hildebrant em $1986,{ }^{21}$ propõe a possibilidade de uma co-decisão, uma interação entre o professor e aluno - em diferentes etapas de ensino que incluem a escolha dos conteúdos, o planejamento, determinação dos objetivos, desta forma auxiliando na resolução de problemas. Tal método criou novos sentidos às aulas de educação física escolar, no que se refere a jogo, movimento, esporte e prática docente. ${ }^{21}$ Esta proposta poderia incluir nas aulas de educação física todos os alunos, pois a participação em todas as fases do processo educacional extinguira os critérios que comumente excluem os alunos das aulas de educação física, ou pelo menos poderiam ser minimizados. ${ }^{21}$

A proposta da motricidade humana elaborada por Manoel Sérgio em 1990, ${ }^{22}$ como teoria para educação física, propõe uma mudança de participação nas aulas de educação física de uma participação elitista para uma participação em massa, propõe a modificação da visão do rendimento para a vivência do prazer e do lazer, tendo como objetivo a auto-superação. Nesta proposta todos os alunos podem participar, pois como objetiva a auto-superarão, os alunos não serão comparados uns aos outros e sim terão como objetivo melhorar a sua participação, vivenciar o movimento e não chegar a um patamar pré-estabelecido ou padronizado como ideal. ${ }^{22}$

Outra proposta para as aulas de educação física é a abordagem sistêmica elaborada por Betti em $1991,{ }^{23}$ que propõe como eixo principal integrar o aluno nas práticas corporais, ressaltando o princípio da não exclusão e da diversidade de conteúdos, segundo o qual nenhuma atividade poderá excluir qualquer aluno das aulas da Educação Física como uma tentativa de reverter à seleção entre aptos e inaptos para as práticas corporais. O princípio da diversidade, apontado na nesta abordagem, propõe que a Educação Física na escola ofereça atividades diferenciadas e não trabalhe apenas com um tipo de conteúdo, objetivando proporcionar vivências nas atividades esportivas, atividades rítmicas e expressivas vinculadas à dança e atividades da ginástica. Apesar da proposta da Conexões: revista da Faculdade de Educação Física da UNICAMP, Campinas, v. 10, n. 2, p. 180-195 maio/ago. 2012.186 ISSN: 1983-9030 
diversidade de conteúdo, o planejamento das aulas deve possibilitar a participação de todos os alunos, independente da limitação motora, física, cognitiva ou qualquer outra limitação que o aluno possa apresentar, ${ }^{1}$ desta forma a abordagem sistêmica se mostra claramente favorável à inclusão, não só de alunos com necessidades espeicias, mas de todos os alunos.

Independente de habilidade motora, nível de desenvolvimento físico ou cognitivo, ou mesmo questões relacionadas ao estado de saúde ou deficiência, a proposta dos Jogos Cooperativos, está baseada na troca da competição para a cooperação, possibilitando assim que os menos hábeis sejam incluídos, pois não há a necessidade exclusiva de vencer, segundo os princípios elaborados por Brotto, teórico desta proposta. Esta abordagem inclui o sentimento de aceitação mútua, favorecendo a real inclusão de todos os alunos nas aulas de educação física escolar. ${ }^{24}$

Os jogos são de grande importância para os alunos durante a vida escolar, os jogos podem apresentar duas versões: a inclusão que propõe os jogos cooperativos e os jogos de "Exclusão" que apresentam um caráter competitivo, priorizando os conceitos das capacidades e habilidades motoras tais como: agilidade, destreza, força, eficiência, velocidade, equilíbrio, dentre outras, o que pode desmotivar a ampla participação nas aulas de educação física.

Com o objetivo principal de despertar e criar no aluno o gosto pelo exercício, Guedes apresenta uma nova abordagem para a educação física intitulada Saúde Renovada. Esta abordagem busca conscientizar o aluno sobre a necessidade de conhecer os benefícios da à atividade física relacionada à saúde e a qualidade de vida. Esta abordagem pode incluir todos os alunos pelo seu caráter individual, onde cada aluno realizará a atividade proposta dentro das suas características e limites individuais. ${ }^{25}$ Também considerando importante por parte do professor de educação física a adoção de uma nova postura pedagógica procurando objetivar metas relacionadas à promoção da saúde, através da seleção, organização e desenvolvimento de experiências/atividades que possam propiciar mais atividade física para crianças e jovens, bem como a opção por um estilo de vida mais ativo e saudável para vida toda. ${ }^{25}$

A Educação física plural, enquanto proposta para educação física escolar foi elaborada por Daolio ${ }^{26}$ no ano de 1995 e entende o movimento como técnica corporal construída e definida culturalmente e que se caracteriza pelo seu meio social, propondo o atendimento a totalidade dos alunos sem exclusão durante todo o processo de ensino e aprendizagem, independente da atividade proposta ou das características dos alunos. Sugere também considerar a pluralidade e as diferenças para que as Conexões: revista da Faculdade de Educação Física da UNICAMP, Campinas, v. 10, n. 2, p. 180-195 maio/ago. 2012.187 ISSN: 1983-9030 
práticas de determinados grupos não sejam vistos como certo ou errado, como melhor ou pior, oferecendo aos alunos uma base motora adequada a partir da qual o aluno possa praticar de forma adequada as diferentes formas de atividade motora. Assim, a educação física plural destaca claramente a necessidade da inclusão de todos os alunos, desde a escolha do conteúdo, até a execução das atividades propostas.

Os Parâmetros Curriculares Nacionais (PCN), apesar de não ser uma abordagem específica da educação física, recebe um destaque neste texto, por auxiliarem o professor na tarefa de reflexão e discussão de aspectos da prática pedagógica diária, ou seja a desenvolverem suas abordagens pedagógicas baseadas nos ditames dos PCN. Segundo os PCN, que tem a inclusão como um dos seus princípios, a Educação Física na escola é responsável pela formação de alunos para que estejam aptos a participar e organizar atividades corporais, adotando atitudes de respeito mútuo, desfrutando das diferntes manifestações da cultura corporal, padrões de beleza e de desempenho; adotando hábitos saudáveis. $^{27}$

O princípio da inclusão, que é ressaltado nos PCN, segundo Seabra Jr. e Araújo ${ }^{15}$ pode contribuir para minimizar as diferenças, sejam elas sociais, culturais ou físicas, objetivando uma mudança no eixo paradigmático da valorização dos mais habilidosos, que ainda está presente na educação física escolar. Para que a inclusão seja efetiva, estes autores sugerem que esta deve uma meta do professor de educação física, ao sistematizar objetivos, propor conteúdos e durante a execução das atividades.

A inclusão, por intermédio do professor, deverá favorecer, adaptar, orientar e estimular a participação de todos os alunos nas aulas de educação física visando à reversão do quadro da educação física baseada na seleção entre indivíduos aptos e inaptos para as praticas corporais, que valorizava apenas o desempenho e eficiência. ${ }^{15}$

Outro princípio importante proposto pelos PCN é o princípio da diversidade, o qual orienta a escolha de objetivos e conteúdos, visando ampliar as relações entre os conhecimentos da cultura corporal de movimento, destacando que o processo de ensino e aprendizagem deve considerar as características dos alunos em todas as suas dimensões - cognitivas, corporal, afetiva, ética, estética, de relação interpessoal e inserção social, o que abrange considerar todos os aspectos dos alunos, inclusive suas deficiências ou dificuldades. ${ }^{27}$ 
Seabra Jr. e Araújo ${ }^{15}$ destacam que em alguns aspectos descritos pelos PCN, nos seus documentos para educação física, incluem propostas, ideias e concepções embasadas em diferentes abordagens da educação física, como a compreensão do processo de ensino e aprendizagem, desenvolvimento humano e das habilidades motoras (abordagem desenvolvimentista), o resgate aos jogos e brincadeiras presentes na cultura infantil (abordagem construtivista), a pluralidade cultural, a cultura corporal, aspectos sócio-históricos (abordagem crítico-superadora), a necessidade de compreensão dos benefícios da atividade física e do esporte (abordagem da saúde renovada) e a não exclusão (abordagem sistêmica), demonstrando a preocupação com o desenvolvimento das múltiplas dimensões do ser humano dentro da especificidade da educação física.

Independente da abordagem, atividade ou estratégia utilizada pelo professor de educação física ao atuar em ambiente escolar, Mantoan ${ }^{4}$ relembra que se torna imperativo a busca por novos caminhos educacionais que atendam à pluralidade do coletivo escolar.

A criatividade no trabalho pedagógico pode ser uma ferramenta eficaz no auxílio do planejamento e execução de aulas mais atrativas, prazerosas e acessíveis à diversidade dos alunos. $\mathrm{O}$ atendimento à pluralidade do coletivo escolar pode apresentar dificuldades que exigem do professor desdobramento, agilidade na execução de novas atividades devido a situações singulares ou adversas que clamam por novas estratégias e respostas, por vezes imediatas, evidenciando-se neste momento a importância da criatividade no trabalho pedagógico. Mitjáns Martínez, ${ }^{28: 70}$ caracteriza de forma geral a criatividade no trabalho pedagógico do professor como "as formas de realização deste que representam algum tipo de novidade e que resultam valiosas para a aprendizagem e o desenvolvimento dos alunos".

A necessidade de solução rápida dos problemas e de busca por novas e eficazes alternativas, pode estimular a criatividade dos professores de Educação Física e no pensamento de De Bono, ${ }^{29}$ este fato pode ser favorável à criatividade, que inclui na definição de alguns autores, a flexibilidade, fluência, capacidade de redefinição, analise e síntese de pensamento, procura de soluções novas, formulação de soluções possíveis, avaliação e teste destas soluções, ${ }^{30}$ combinação de informações conhecidas, domínio de referências ${ }^{31}$ entre outros múltiplos aspectos.

Mitjáns Martínez ${ }^{32}$ aponta que a criatividade é um processo complexo da subjetividade humana na sua simultânea condição de subjetividade individual e subjetividade social é nesse sentido que as 
exigências da prática junto a importantes recursos subjetivos desenvolvidos pelos professores no percurso de sua historia de vida podem se articular para uma ação pedagógica criativa. A necessidade de ações criativas, que se apresenta no cotidiano dos professores perante a complexidade da ação docente e da diversidade dos alunos com os quais trabalha, pode ser um importante estimulo para a expressão da criatividade no trabalho pedagógico, sempre que o professor possa expressar sua condição de sujeito ativo e mobilizar recursos subjetivos perante as demandas da situação.

A estimulação e o desenvolvimento da criatividade dos professores tornam-se extraordinariamente importantes já que a criatividade no trabalho pedagógico poderá apresentar novos caminhos que atendam à pluralidade do coletivo escolar numa perspectiva verdadeiramente inclusiva da educação e como parte dela, a Educação Física.

Outro aspecto importante no processo de inclusão é perceber que a diversidade não é um problema, inclusive pode ser encarada como uma oportunidade de enriquecimento do processo de ensinoaprendizagem. Pensar a Educação Física Inclusiva não é apenas refletir sobre as possibilidades de atividades para alunos com necessidades especiais e sim falar sobre a participação de todos os alunos sem exclusão, seja por inabilidade, gênero, biótipo ou limitações motoras. Desta forma concordamos com Daolio ${ }^{26}$ ao ressaltar que todos os alunos, independentemente de suas diferenças, são iguais quanto ao direito à prática da atividade física.

\section{CONSIDERAÇÕES FINAIS}

Neste texto foram realizadas constatações e inferências sobre a preocupação com a necessidade de “inclusão" nas abordagens pedagógicas da educação física, evidenciando-se que a maioria delas, não apresenta evidencias claras sobre como a inclusão deveria acontecer, existindo em algumas das abordagens apenas a ideia de "não exclusão".

Dentro das abordagens pedagógicas da educação física citadas anteriormente, algumas poderiam ser consideradas "mais produtivas" para a inclusão de todos os alunos nas aulas de educação física, considerando seus princípios, temos a abordagem desenvolvimentista por apontar a necessidade do aluno em aumentar o repertório motor, cognitivo, afetivo e social. A abordagem crítico-superadora e o ensino aberto que sugerem a participação em todas as etapas do processo educacional para que o aluno possa ampliar seu conhecimento sobre a cultura de movimento e assim as atividades seriam 
mais adequadas às características dos alunos, facilitando a inclusão de todos os alunos nas aulas de educação física. Outras como a crítico-emancipatória e a sistêmica ressaltam a participação aberta e a não exclusão, sendo estes princípios base fundamentais para a inclusão.

As diferentes abordagens pedagógicas, inclusive os documentos dos PCN possibilitam ao professor "passear" entre as diferentes abordagens existentes na educação física, utilizando uma em específico, ou mesmo a união de princípios de diferentes abordagens. O que o professor deve ter em mente durante todo o processo educacional, é o direito a participação ativa e total nas aulas de educação física, que pertence à todos os alunos.

Apesar das novas abordagens da educação física favorecer o princípio da inclusão, ainda é notória nestas aulas a exclusão de alunos por diferentes motivos. Nardim e Menezes ${ }^{33}$ evidenciaram o reconhecimento por parte dos docentes de que possuem dificuldades em trabalhar com alunos com necessidades especiais, associadas às relações negativas que dos professores frente à deficiência, ${ }^{34}$ ou insegurança por falta de formação para trabalhar com as diferenças existentes no ambiente escolar. ${ }^{33}$

A inclusão será favorecida quando o professor de educação física escolar passar por um processo de formação, para que possa conhecer o assunto, para incorporar a inclusão na sua prática pedagógica diária.

As diferenças que existem e existirão entre os alunos durante uma aula de educação física, bem como perante as possibilidades de atuação da educação física, quando relacionadas às diferentes abordagens e propostas pedagógicas, reforçam que o profissional de educação física, em especial na educação física escolar, deve estar atento, identificando-as, reconhecendo-as, tornando-as parte do processo de ensino-aprendizagem para que as atividades propostas possibilitem a participação de todos os alunos, sem exclusão.

Pensando na possibilidade de inclusão de todos os alunos, Rodrigues ${ }^{34}$ destaca que a "dispensa" das aulas pode ser a expressão da dificuldade que os professores tem de criar alternativas positivas e motivadoras para os alunos que apresentam alguma dificuldade. A dispensa, algumas vezes ocorre sem que o professor seja consultado, sem que sejam estudadas outras possibilidades de participação nas aulas de educação física. Vale lembrar que se um aluno apresentar dificuldades em alguma disciplina, ele não é dispensado e sim recebe reforço na esta matéria. A dispensa deve ocorrer 
somente em casos muito específicos, onde haja contra indicação total à prática de atividade física ou à participação nas aulas de educação física.

Rodrigues $^{34}$ aponta que com criatividade, pode-se usar o corpo, o movimento, o jogo, a dança e o desporto como oportunidade de celebrar as diferenças e proporcionar aos alunos experiências que realcem a cooperação e a solidariedade. Complementando este pensamento, Soler $^{5}$ indica que a educação física não pode separar pessoas por possuírem habilidades e sim propiciar habilidades a todos.

As reflexões anteriormente expostas são relevantes, pois as crianças passam grande parte da infância e adolescência na escola e neste período freqüentam as aulas de educação física, que podem deixar lembranças prazerosas e de sucesso, outras de algo ruim, exclusão ou incompetência. Cabe aos professores, com criatividade, contribuir para a construção de lembranças positivas, com motivação e gosto pela atividade física, dada sua importância durante toda a vida escolar.

\section{REFERÊNCIAS}

${ }^{1}$ DARIDO, S. C. Ação pedagógica do professor de Educação Física. 1997. Tese (Doutorado) Instituto de Psicologia, Universidade de São Paulo, São Paulo, 1997.

${ }^{2}$ MARTINS, A. S. Educação Física Escolar: Novas tendências. Revista Mineira de Educação Física, Viçosa, v. 10, n. 1, 2002.

${ }^{3}$ FARIA JUNIOR, A. G. A reinserção dos jogos populares nos programas escolares. Motrivivência, Florianópolis, n. 9, 1996.

${ }^{4}$ MANTOAN, M. T. E. Integração X inclusão: educação (de qualidade) para todos. Porto Alegre, Revista Pátio, v. 5, p. 48-51, 1998.

${ }^{5}$ SOLER, R. Educação Física inclusiva na escola em busca de uma escola plural. Rio de Janeiro; Sprint, 2005. 
${ }^{6}$ DARIDO, S. C. Educação Física na escola: questões e reflexões. Rio de Janeiro: Guanabara Koogan, 2003.

${ }^{7}$ MARINHO, I. P. História geral da Educação Física. São Paulo: Companhia Brasil, 1980.

${ }^{8}$ COSTA, V. L. F. Prática da Educação Física no primeiro grau. São Paulo: Ibrasa, 1984.

${ }^{9}$ SOUZA JÚNIOR, M. O saber e o fazer pedagógicos: a Educação Física como componente curricular? Isso é história? Recife: EDUPE,1999.

${ }^{10}$ SOARES, C.L. et al. Metodologia do ensino de Educação Física. São Paulo: Cortez, 1992.

${ }^{11}$ CASTELlani FILHO, L. Educação Física no Brasil: a história que não se conta. Campinas: Papirus, 1994.

${ }^{12}$ DARIDO, S. C.; SANCHES NETO, L. O contexto da Educação Física na Escola. In: DARIDO, S. C.; RANGEL, I. C. A. (Coord.). Educação física na escola: implicações para prática pedagógica. Rio de Janeiro: Guanabara Koogan, 2005.

${ }^{13}$ RESENDE, H. G. Necessidade da educação motora na escola. In: DE MARCO, A. (Org.). Pensando a educação motora. Campinas: Papirus, 1995.

${ }^{14}$ DARIDO, S. C. A educação física, a formação do cidadão e os parâmetros curriculares nacionais. Revista Paulista de Educação Física, São Paulo, v. 15 n. 1, p. 17-30, 2001.

${ }^{15}$ SEABRA JR., L. Inclusão, necessidades especiais e educação física: considerações sobre a ação pedagógica no ambiente escolar. 2006. Dissertação (Mestrado em Educação Física) - Faculdade de Educação Física, Universidade Estadual de Campinas, Campinas, 2006.

${ }^{16}$ FREIRE, J. B. Educação de corpo inteiro: teoria e prática da Educação Física. São Paulo: Scipione, 1989.

${ }^{17}$ TANI, G, et al. Educação Física escolar: fundamentos de uma abordagem desenvolvimentista. São Paulo: EDUSP, 1988.

Conexões: revista da Faculdade de Educação Física da UNICAMP, Campinas, v. 10, n. 2, p. 180-195 maio/ago. 2012.193 ISSN: 1983-9030 
${ }^{18}$ TANI, G. Perspectivas para a Educação Física escolar. Revista Paulista de Educação Física, São Paulo, v. 5, n.1/2, p. 61-69, 1991.

${ }^{19}$ KUNZ, E. Transformação didático-pedagógica do esporte. Ijuí: Ed. da Unijuí. 1996.

${ }^{20}$ KUNZ, E. Educação Física: ensino \& mudanças. Ijuí: Ed. da Unijuí, 1991.

${ }^{21}$ HILDEBRANDT, R. Concepções abertas no ensino da Educação Física. Rio de Janeiro. Ao Livro Técnico, 1986.

${ }^{22}$ SÉRGIO, M. A motricidade humana: uma revolução científica. Motrivivência, Florianópolis, n. 3, 1990.

${ }^{23}$ BETTI, M. Educação Física e sociedade. São Paulo: Movimento, 1991.

${ }^{24}$ BROTO, F. O. Jogos cooperativos: se o importante é competir, o fundamental é cooperar. São Paulo: Cepeusp, 1995.

${ }^{25}$ GUEDES, D. P.; GUEDES, J. E. R. P. Subsídios para implementação de programas direcionados à promoção da saúde através da Educação Física Escolar. Revista da Associação de Professores de Educação Física de Londrina, Londrina, v. 8, n.15 p. 3-11,1993

${ }^{26}$ DAOLIO, J. Da Cultura do corpo. Campinas: Papirus, 1995.

${ }^{27}$ BRASIL. Ministério da Educação e Cultura. Parâmetros curriculares nacionais: terceiro e quatro ciclos do ensino fundamental - educação física. Disponível em: http://portal.mec.gov.br/seb/arquivos/pdf/fisica.pdf capturado 1996.

${ }^{28}$ MITJÁNS MARTÍNEZ, A. Criatividade no trabalho pedagógico e criatividade na aprendizagem: uma relação necessária? In: TACCA, M. C. (Org.). Aprendizagem e trabalho pedagógico. Campinas: Alínea, 2006. 
${ }^{29}$ DE BONO, E. Criatividade levada a sério: como gerar idéias produtivas através do pensamento lateral. São Paulo: Pioneira, 1997.

${ }^{30}$ TORRANCE, E. P.; GOFF, K. Fosteringing academic creativity in gifted students. (on line) Disponível em: http:/www.creativityresearch.comInternet. 1999.

${ }^{31}$ DIECKERT, J. Criatividade em Educação Física: elementos e princípios da Educação Física. Rio de Janeiro: Ao Livro Técnico, 1986.

${ }^{32}$ MITJÁNS MARTÍNEZ, A. La interrelación entre investigación psicológica y práctica educativa: un análisis crítico a partir del campo de la creatividad. In: DEL PRETTE, Z. (Org.). Psicologia escolar/educacional : saúde e qualidade de vida : explorando fronteiras . Campinas : Átomo, 2011.

${ }^{33}$ NARDIM, A. C.; MENNEZES, E. P. Representações docentes: o olhar para o aluno com necessidades educacionais especiais. Educação Especial, Santa Maria, v. 31, p.63-74, 2008.

${ }^{34}$ RODRIGUES, D. Atividade motora adaptada: a alegria do corpo. São Paulo: Artes Médicas, 2006.

Recebido em: 05 outubro 2011.

Aceito em: 11 julho 2012. 